\title{
COVID-19 Pandemic Disruption on the Management of Tuberculosis Treatment in Indonesia
}

\author{
Gabriella J Caren', Deni Iskandar $\mathbb{D}^{2,3}$, Dian AE Pitaloka', Rizky Abdulah $\mathbb{D}^{1,4}$, Auliya A Suwantika $\mathbb{D}^{1,4,5}$ \\ 'Department of Pharmacology and Clinical Pharmacy, Faculty of Pharmacy, Universitas Padjadjaran, Bandung, Indonesia; ${ }^{2}$ Unit of Global Health, \\ Department of Health Sciences, University Medical Center Groningen (UMCG), University of Groningen, Groningen, the Netherlands; ${ }^{3}$ Faculty of \\ Pharmacy, Bhakti Kencana University, Bandung, Indonesia; ${ }^{4}$ Centre of Excellence in Higher Education for Pharmaceutical Care Innovation, Universitas
} Padjadjaran, Bandung, Indonesia; ${ }^{5}$ Center for Health Technology Assessment, Universitas Padjadjaran, Bandung, Indonesia

Correspondence: Auliya A Suwantika, Department of Pharmacology and Clinical Pharmacy, Faculty of Pharmacy, Universitas Padjadjaran, Jl. Raya Bandung-Sumedang Km. 21, Jatinangor, Bandung, Sumedang, 45363, Indonesia, Email auliya@unpad.ac.id

\begin{abstract}
The current coronavirus disease 2019 (COVID-19) situation might deteriorate the efforts to eliminate tuberculosis (TB) in Indonesia. This study aimed to review the COVID-19 pandemic disruption on the management of TB treatment in Indonesia. We identified several disruptions due to the pandemic on TB control management. Firstly, there is a potential decrease in the funding for TB treatment. Financial disruptions caused by the COVID-19 pandemic have led to further setbacks. In many countries, including Indonesia, financial and other resources have been reallocated from TB to the COVID-19 response. Secondly, it has been highlighted that all TB services, including case detection and rapid diagnostic, have been disrupted by the pandemic. Thirdly, the pandemic would be associated with the lower quality of care and treatment for TB in Indonesia. It might decrease the enthusiasm of patients with TB, multi-drug resistant (MDR)-TB, and TBhuman immunodeficiency virus (HIV) to visit TB hospitals because of social distancing measures by the government. Finally, the COVID19 pandemic also has impacted critical activities of monitoring, evaluation, and surveillance. There are several lessons from other countries about managing TB treatment during the pandemic, such as combining screening for COVID-19 and TB by applying x-ray technology and artificial intelligence-based software. In addition, the use of telemedicine or telehealth in TB treatment is also beneficial to deliver medication, assess patients' progress, and inform prevention strategies. To reach the target with the end TB strategy, the government of Indonesia can adopt the World Health Organization's (WHO's) comprehensive strategies, such as integrated, patient-centered TB care and prevention strategies; bold policies and supportive systems; and intensified research and innovations.
\end{abstract}

Keywords: fixed-dose combination, rapid diagnostic, MDR-TB, telemedicine, national TB program

\section{Introduction}

Indonesia is the second country with the highest number of annual tuberculosis (TB) incidents, and it has become a national problem since the last decade. ${ }^{1}$ To eliminate TB by 2035 , the government has implemented a national TB control program since 1995. Nevertheless, the annual number of new TB cases increased to 25.40 per 1 million population with a treatment success rate of $88 \%$, as reported in $2017 .{ }^{2}$ Several identified problems contributed to this situation, such as diagnosis delay and non-adherence to treatment. ${ }^{3}$ The current coronavirus disease 2019 (COVID-19) situation might deteriorate the efforts to eliminate TB in Indonesia.

The emergence of the current pandemic, particularly in Indonesia, posed a new challenge to control infectious diseases. According to the latest data, the number of COVID-19 infection cases in Indonesia was estimated to be $1,657,035$, with average daily new cases of $5241,{ }^{4}$ which affected the healthcare system. ${ }^{5}$ As an infectious disease, COVID-19 is caused by the highly contagious SARS-CoV-2 virus, ${ }^{1}$ which is transmissible through droplets, either directly or indirectly. ${ }^{5}$ At present, approximately 149 million positive cases of COVID-19 in all age groups have been recorded worldwide. ${ }^{4}$

Similarly, TB is caused by Mycobacterium tuberculosis that can be transmitted through droplets as well. As one of Indonesia's leading infectious diseases, TB affects all age groups, specifically the productive age group (15-54 years). ${ }^{6}$ 
To achieve a world free of TB, the United Nations (UN) has targeted to end the TB epidemic by 2030, as mentioned in the Sustainable Development Goals (SDGs). ${ }^{7}$ The World Health Organization (WHO) also has set an ambitious target to reduce the number of TB deaths and incidence rate by $95 \%$ and $90 \%$, respectively, by $2035 .^{7}$ In addition, TB-affected families facing catastrophic costs due to TB was targeted to be $0 \%$ (see Table 1$)^{7}$

Although TB elimination progress in Indonesia is continuing towards achieving these targets, the current pandemic could be a significant challenge to accelerate the efforts. The pandemic would impact the management of TB control in Indonesia. Hence, a comprehensive strategy is required to mitigate its medium or long-term impact. ${ }^{8,9}$ This study aimed to review the COVID19 pandemic disruption on the management of TB treatment in Indonesia.

\section{Management of TB Treatment in Indonesia}

\section{Guidelines of TB Treatment in Indonesia}

Anti-TB drugs are used to prevent further transmission of disease. The treatment also aims to maintain quality of life, prevent relapse and more severe TB cases. There are two stages of TB treatment, which are the initial and advanced phases. Both phases are carried out within a specific timeframe. The initial phase treatment aims to reduce the number of bacteria present in the body, while the advanced phase eradicates the remaining bacteria so that the patients can recover and not relapse. There are several recommended first- and second-line anti-TB drugs in both phases. The first-line antiTB drugs are isoniazid, rifampicin, pyrazinamide, streptomycin, and ethambutol. The second-line anti-TB drugs are levofloxacin, moxifloxacin, kanamycin, capreomycin, ethionamide, clofazimine, linezolid, bedaquiline, and paraaminosalicylic acid. ${ }^{10,11}$

Guidelines of TB treatment in Indonesia recommend combinations of anti-TB drugs, which are classified into four categories: category 1, 2, pediatric, and patients with drug-resistant TB. Categories 1 and 2 are intended for new anti-TB drugs sensitive and TB-diagnosed patients (eg, patients who had interrupted treatment and patients who did not succeed with the treatment in category 1, or experienced a relapse). In addition, the fixed-dose combinations for patients in categories 1, 2 , and pediatric are based on the body weight. To be applied in drug-resistant TB patients, these combinations are based on the results of the rapid molecular test. More information about fixed-dose combinations for TB treatment in all categories can be seen in Table 2.

\section{Relevant Issues on TB and COVID-19 Treatment}

Although the surveillance should make an integrative report of infectious diseases, there is a lack of comprehensive information on TB and COVID-19 cases in Indonesia. This current pandemic has led to a significant fall in the number of successful TB treatments. ${ }^{12}$ Next to the ability on impacting the national healthcare system, TB and Covid-19 are airborne transmissible diseases, which can be diagnosed rapidly through rapid testing and require effective prevention, diagnosis, and treatment strategies. For both diseases, screening symptoms, including cough, fever, shortness of breath, and nucleic acid amplification tests (NAAT), are recommended as the preliminary test. In addition, sputum tests and chest radiography are used to identify active TB patients, while Xpert MTB-RIF is applied to identify anti-TB resistance cases. ${ }^{13}$ On the other hand, the gold standard of COVID-19 diagnostic is nasopharyngeal or oropharyngeal swabs to

Table I Indicators, Milestones and Targets to End the Global TB Epidemic. ${ }^{7}$

\begin{tabular}{|l|l|l|l|l|}
\hline \multirow{2}{*}{ Indicators } & \multicolumn{2}{l|}{ Milestones } & \multicolumn{2}{l|}{ Targets } \\
\cline { 2 - 5 } & $\mathbf{2 0 2 0}$ & $\mathbf{2 0 2 5}$ & $\mathbf{2 0 3 0}$ & $\mathbf{2 0 3 5}$ \\
\hline Reduction in number of TB deaths* & $35 \%$ & $75 \%$ & $90 \%$ & $95 \%$ \\
\hline Reduction in TB incidence rate* & $20 \%$ & $50 \%$ & $80 \%$ & $90 \%$ \\
\hline TB-affected families facing catastrophic costs due to TB & $0 \%$ & $0 \%$ & $0 \%$ & $0 \%$ \\
\hline
\end{tabular}

Note: *Compared with 2015. 
Table 2 Fixed Dose Combinations for TB Patients

\begin{tabular}{|c|c|c|c|}
\hline Body Weight (kg) & \multicolumn{2}{|c|}{ Initial Phase } & Advanced Phase \\
\hline \multirow[t]{2}{*}{ Category I } & \multicolumn{2}{|l|}{56 days } & 16 weeks \\
\hline & \multicolumn{2}{|c|}{ HRZE (75/I50/400/275) } & $\operatorname{HR}(75 / I 50)$ \\
\hline $30-37$ & \multicolumn{2}{|l|}{2 tablets } & 2 tablets \\
\hline $38-54$ & \multicolumn{2}{|l|}{3 tablets } & 3 tablets \\
\hline $55-70$ & \multicolumn{2}{|l|}{4 tablets } & 4 tablets \\
\hline$\geq 71$ & \multicolumn{2}{|l|}{5 tablets } & 5 tablets \\
\hline \multirow[t]{2}{*}{ Category 2} & 28 days & 56 days & 20 weeks \\
\hline & HRZE & (HRZE)S $(75 / 150 / 400 / 275)+S$ & $\operatorname{HRE}(75 / 150 / 275)$ \\
\hline $30-37$ & 2 tablets & 2 tab HRZE, 500 mg streptomycin inj & 2 tablets \\
\hline $38-54$ & 3 tablets & 3 tab HRZE, 750 mg streptomycin inj & 3 tablets \\
\hline $55-70$ & 4 tablets & 4 tab HRZE, 1000 mg streptomycin inj & 4 tablets \\
\hline$\geq 71$ & 5 tablets & 5 tab HRZE, 1000 mg streptomycin inj & 5 tablets \\
\hline \multirow[t]{2}{*}{ Paediatric } & \multicolumn{2}{|l|}{2 months } & 4-10 months \\
\hline & \multicolumn{2}{|c|}{ HRZ (75/50/I50) } & HR $(75 / 50)$ \\
\hline $5-7$ & \multicolumn{2}{|l|}{ I tablet } & I tablet \\
\hline $8-11$ & \multicolumn{2}{|l|}{2 tablets } & 2 tablets \\
\hline $12-16$ & \multicolumn{2}{|l|}{3 tablets } & 3 tablets \\
\hline $17-22$ & \multicolumn{2}{|l|}{4 tablets } & 4 tablets \\
\hline $23-30$ & \multicolumn{2}{|l|}{5 tablets } & 5 tablets \\
\hline$>30$ & \multicolumn{3}{|c|}{ Follow adult anti-tuberculosis drug guidelines } \\
\hline \multirow[t]{2}{*}{ New patients of drug-resistant TB treatment or treated for $<1$ month } & \multicolumn{2}{|l|}{8 months } & $12-14$ months \\
\hline & \multicolumn{3}{|c|}{$\mathrm{Km}-\mathrm{Mfx}-\mathrm{Pto}-\mathrm{H}-\mathrm{Cfz}-\mathrm{E}-\mathrm{Z} / 5 \mathrm{Mfx}-\mathrm{Cfz}-\mathrm{E}-\mathrm{Z}$} \\
\hline Drug resistant TB & \multicolumn{3}{|c|}{$20-26$ months } \\
\hline Rifampicin resistant or MDR-TB & \multicolumn{3}{|c|}{ Km - Lfx - Eto - Cs - Z- (E) - (H)/Lfx- Eto - Cs - Z- (E) - (H) } \\
\hline Kanamycin resistant & \multicolumn{3}{|c|}{ Cm-Lfx-Eto-Cs-Z-(E)-(H)/Lfx- Eto-Cs-Z-(E)-(H) } \\
\hline \multirow[t]{2}{*}{ Fluoroquinolones resistant } & \multicolumn{3}{|c|}{ Km-Mfx-Eto-Cs-PAS-Z-(E)-(H)/Mfx-Eto-Cs-PAS-Z-(E)-(H). } \\
\hline & \multicolumn{3}{|c|}{ Km - Eto-Cs-PAS-Z-(E)- Bdq/Eto-Cs-PAS-Z-(E) } \\
\hline Second line injection resistant & \multicolumn{3}{|c|}{ Lfx-Eto-Cs-PAS-Z-(E)-Bdq/Lfx-Eto-Cs-PAS-Z-(E) } \\
\hline \multirow[t]{2}{*}{ Kanamycin and fluoroquinolones resistant } & \multicolumn{3}{|c|}{ Mfx-Eto-Cs-PAS-Z-(E)-(H)/Mfx-Eto-Cs-PAS-(E)-(H) } \\
\hline & \multicolumn{3}{|c|}{ Eto-Cs-PAS-Z-(E)-Bdq- Lnz- Cfz/Eto-Cs-PAS-Z-(E)-Lnz-Cfz } \\
\hline
\end{tabular}

Abbreviations: $\mathrm{H}$, isoniazid; R, rifampicin; Z, pyrazinamide; S, streptomycin; $\mathrm{E}$, ethambutol; Lfx, levofloxacin; Mfx, moxifloxacin; Km, kanamycin; Cm, capreomycin; Eto, etionamide; Cfz, clofazimine; Lzd, linezolid; Bdq, bedaquiline; PAS, para-aminosalicylic acid. 
identify the virus's genetic material by Reverse Transcription-Polymerase Chain Reaction (RT-PCR). ${ }^{6}$ The potential use of saliva or sputum for COVID-19 is currently being further explored.

In Indonesia, curative treatment regimens have been established by considering several first-line drugs, such as isoniazid, rifampicin, ethambutol, and pyrazinamide. ${ }^{10}$ Drug regimens can be completed at home with regular follow-up visits to the hospital. ${ }^{14}$ For COVID-19 treatment, trials are currently ongoing, and only limited treatments are presently available, including the administration of remdesivir and dexamethasone in severe cases. ${ }^{11,15}$ In particular, $20 \%$ of patients require hospitalizations, and intensive care with invasive mechanical ventilation is required for $5 \%$ of patients who experienced more severe symptoms. ${ }^{16}$ In the context of prevention strategies, various measures to reduce the risk of transmission of COVID-19 and TB at the same time have been implemented at the global, regional, and national levels. These measures are social distancing, cough etiquette, handwashing, and other hygiene campaigns. Specifically, contact tracing of infected individuals is crucial in TB and COVID-19 before community transmission becomes ingrained. ${ }^{16}$

\section{Challenges in Controlling TB During the Pandemic}

Although Indonesia has made a remarkable progress over the last decade, TB remains one of the country's top four causes of death. ${ }^{17}$ An increase in Multi-Drug Resistant (MDR)-TB cases and under-reporting TB cases pose significant challenges to the national program. In particular, the pandemic has dramatically exacerbated the progress of TB treatment in the world. In comparison with the previous year, 1.4 million fewer people in 2020 (approximately $21 \%$ reduction) have been estimated to receive complete TB treatment. ${ }^{18}$ Furthermore, there are several countries with the most significant relative gaps, such as Indonesia (42\%), South Africa (41\%), the Philippines (37\%), and India (25\%). ${ }^{18}$

Following the initiative framework of the Challenge TB project in a collaboration between United States Agency for International Development (USAID) and the Indonesia National TB Program, we identified several potential impacts of COVID-19 on TB control management in Indonesia. Firstly, there is a potential decrease in the funding for TB treatment. From 2017 onwards, domestic financing of TB is dominant, however, the Global Fund holds a vital role. ${ }^{19}$ From 2014 to 2020, Indonesia received approximately US\$ 207 million for TB from the Global Fund. ${ }^{20}$ Because of the COVID-19 situation, TB financing change was apparent between 2019 and 2021. Compared to 2019, there was an approximately $30 \%$ decrease in total financing in 2020. Domestic financing and other sources decreased by $61 \%$ and $72 \%$, respectively, but this situation was compensated with more than double of increased financing from the Global Fund. In addition, domestic financing capacity was significantly affected in 2020, though we can see that it rebounded in $2021 .{ }^{19}$ Currently, we have not yet seen the impact of decreased funding in 2020 on TB service performance. Nevertheless, new innovative financial mechanisms for TB treatment have to be scaled up by the government of Indonesia to regain progress lost in the last two years due to the pandemic and to prevent a resurgence of TB.

Secondly, it has been highlighted that all TB services, including case detection and rapid diagnostic, have been disrupted by the pandemic. Globally, there was approximately $21 \%$ of decreased reported TB cases in 2020, compared to 2019, as COVID-19 stalled the disease's detection. Some of the most significant drops occurred in Indonesia, ${ }^{21}$ reaching $41 \%{ }^{22}$ Programs and activities were suspended when cases were detected, specifically for active case finding (ACF) due to limited guidance on TB-ACF operationalization during the COVID-19 pandemic. For passive case findings, it might be caused by patients' movement limitations to access treatment. These case findings were resumed by using an adapted approach. ${ }^{23}$ Moreover, concern about contracting the virus when visiting health-care facilities also could affect the whole agenda of early diagnosis and seeking care. ${ }^{24}$ These facilities have minimized their services to reduce the risk of transmission. Most TB hospitals in Indonesia have been designated COVID-19 hospitals at provincial levels, leading to a significant delay in TB diagnosis because of additional workload. ${ }^{25}$

Thirdly, the pandemic would be associated with the lower quality of care and treatment for TB in Indonesia. It was hypothesized that COVID-19 exacerbates the TB burden, specifically the mortality rate. However, TB mortality negatively correlates with COVID-19 deaths/million in countries with a TB endemic problem and high BCG vaccine coverage. ${ }^{26}$ Moreover, it might decrease the enthusiasm of patients with TB, MDR-TB, and TB-HIV to visit TB hospitals because of social distancing measures by the government. Using MDR-TB patients to illustrate the impact of the pandemic on lowering the quality of treatment, patients in this group are treated in long term (up to 12 months) with specific regimens and dosages, where they are requested to visit TB hospitals regularly for comprehensive examination 


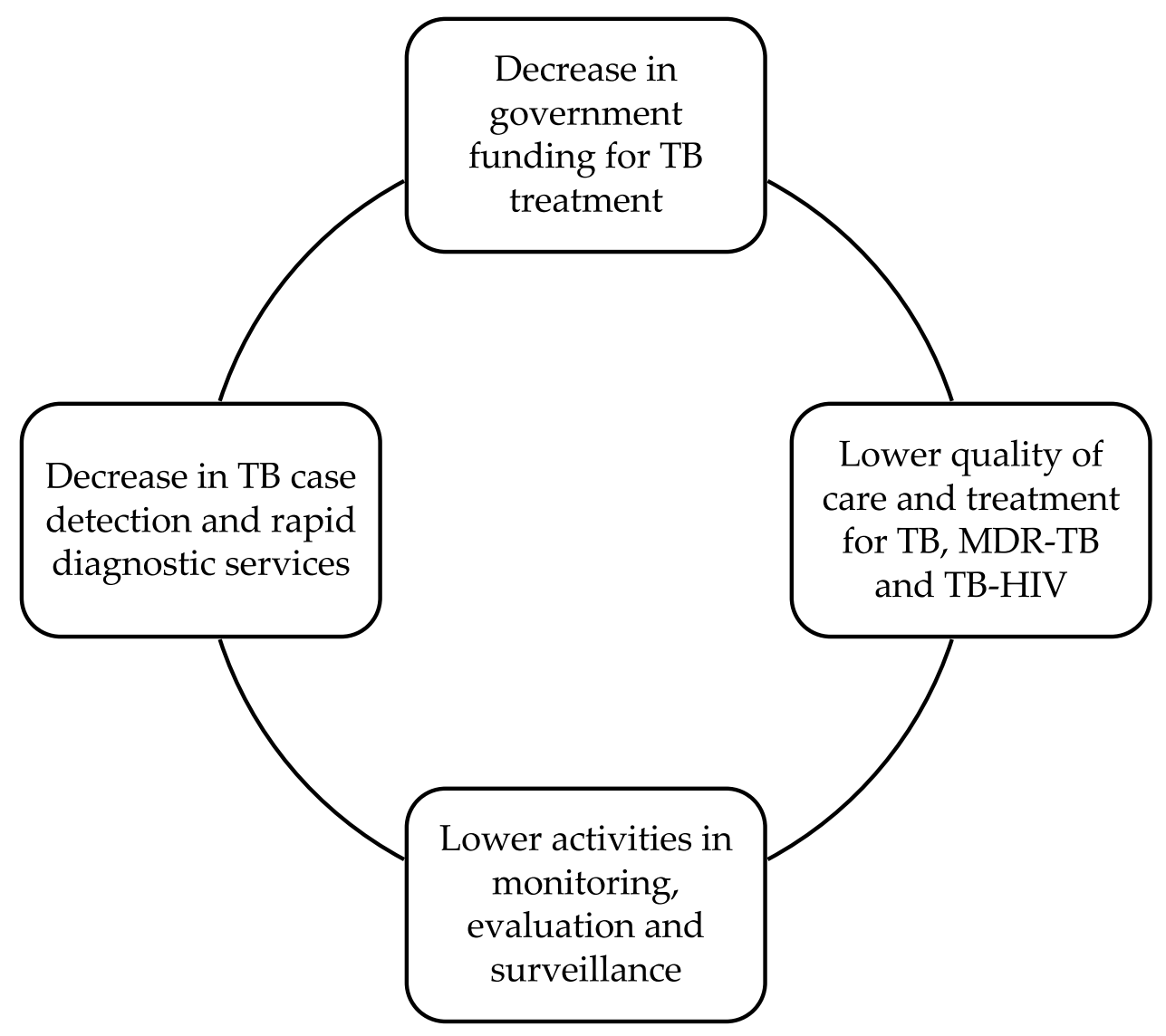

Figure I COVID-19 pandemic disruptions on TB control management in Indonesia.

and treatment. The change in TB hospitals' role in Indonesia has been a significant barrier for these patients to visit hospitals due to the fear of COVID-19 infection. This phenomenon limited the hospital to provide detailed observations on clinical outcomes of MDR-TB patients. ${ }^{27}$

Finally, the COVID-19 pandemic has also impacted critical activities of monitoring, evaluation, and surveillance. In general, private sector work processes were disrupted and changed, putting more stress on health-care workers. Nevertheless, their contribution to support TB services drastically increased since the end of $2020 .{ }^{24}$ These activities could not be implemented because of several factors, such as travel restrictions. This situation might hinder ending TB by 2035, as the UN and WHO targeted. ${ }^{27,28}$ In the context of Indonesia, this might delay efforts to achieve the national goal of the TB Program. ${ }^{29}$ More detailed information about the potential impacts of COVID-19 on TB control management in Indonesia can be seen in Figure 1.

\section{Lessons Learned from Other Countries}

There are several lessons learned from other countries regarding the management of TB treatment during the pandemic. A previous study in the Philippines highlighted that in comparison with TB patients without COVID-19 infection, TB patients with COVID-19 infection had a higher risk of death. ${ }^{30}$ The result of this study confirmed that TB could increase the severity of COVID-19 infection. Hence, prevention strategies should be intensified. ${ }^{30}$ Another study in India confirmed that TB services should be one of the priority services in the health-care facilities during the pandemic by separating areas for TB and COVID-19. TB patients should not interact with COVID-19 patients to avoid virus transmission. ${ }^{31}$ Concerning the diagnostic tool, a TB test along with the COVID-19 test is recommended, and vice versa. Two specimens are required for that purpose since the TB test uses a sputum specimen, while the COVID-19 test uses a nose or throat swab. However, these two tests use the same method of molecular test. ${ }^{30}$ In particular, the number of tools for detection and human resources should be increased to enhance the testing capacity. ${ }^{31}$ In Pakistan, a strategy of 
combining screening for COVID-19 and TB has also been implemented by applying X-ray technology and artificial intelligence-based software, which can assist doctors in making decisions by providing radiographic results. ${ }^{32}$ These approaches can be considered to be implemented in Indonesia to optimize COVID-19 and TB diagnosis efforts.

For TB therapy during the COVID-19 pandemic, outpatient care is more recommended than hospitalization (unless the disease is severe) to avoid nosocomial infections. ${ }^{33}$ In general, therapy for TB patients with COVID-19 is the same as therapy for TB patients without COVID-19. The treatment should be monitored regularly and not be interrupted. Hence, the supply chain management during the pandemic is also critical to ensure no treatment disruption. ${ }^{31}$ In addition, telemedicine or telehealth in TB treatment is beneficial to deliver medication, assess patients' progress, and inform prevention strategies, as implemented in the UK, Australia, Russia, and India. ${ }^{32}$ The use of digital platforms to support the treatment should also be considered to be applied in Indonesia. These platforms can be helpful for the implementation of video-supported treatment, counseling, and monitoring. ${ }^{30,31}$

\section{Discussion}

Reaching the target with the end TB strategy, the WHO recommended a comprehensive strategy that the government of Indonesia can adopt. This strategy provides unified responses to end TB, which is built on three pillars and underpinned by four key principles. These strategic pillars are integrated, patient-centered TB care and prevention strategies, bold policies and supportive systems, and intensified research and innovations. In particular, four key principles should be taken into accounts, such as government stewardship and accountability with monitoring and evaluation; building a solid coalition with civil society and community; protecting and promoting human rights, ethics, and equity; and adaptation of strategy and targets at country level with global collaboration (see Figure 2). ${ }^{7}$

Several guidelines to anticipate the impact of the COVID-19 pandemic on TB treatment have been established to mitigate the COVID-19 pandemic, including the sustainability of TB services and information on similarity, differences, and interactions between both diseases. ${ }^{34-37}$ These documents are essential to tackle TB and COVID-19 at the same time. Several major concerns should be considered in controlling TB during the pandemic, such as administrative controls,

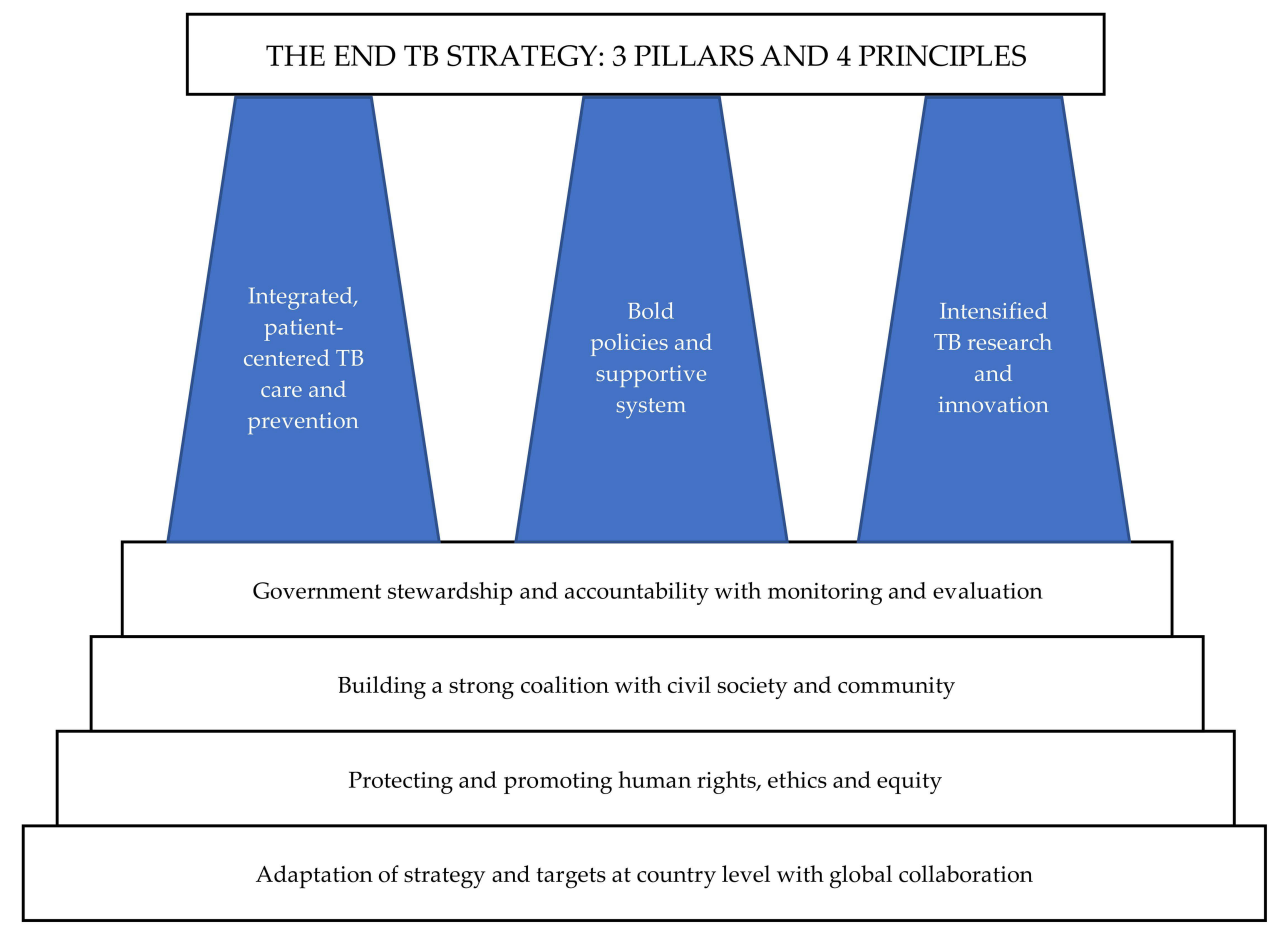

Figure 2 A comprehensive strategy to end TB in Indonesia, which is adapted from WHO's recommendations.

Notes: Adapted with permission from World Health Organization. The End TB Strategy; 2015 [cited 8 February 202I]. Available from: https://www.who.int/tb/End_TB_ brochure.pdf. Accessed January 13, 2022. ${ }^{7}$ (c) World Health Organization 2015. 
environmental controls, and respiratory protection. A set of administrative control is the first and most crucial component of the mitigation strategy, which aims to reduce the exposure and transmission of Mycobacterium tuberculosis during the COVID-19 pandemic. Respiratory hygiene is recommended to those who visit health-care facilities to minimize transmission. In addition, respiratory separation/isolation is also suggested for high-risk groups or patients with early treatment. Health-care facilities can decentralize TB treatment using digital health technologies and provide home-based TB care to increase adherence support, counseling, and follow-up therapy during the pandemic. Another concern is environmental control, which aims to minimize the concentration of infectious droplets in the air by using a particular ventilation system to maximize airflow rates or filtration by using a high-efficiency particulate air (HEPA) filter. Next to administrative and environmental controls, respiratory protection, specifically for health-care staff in a particular area, is also essential to reduce the exposure of Mycobacterium tuberculosis. The use of particulate respirators is recommended to be applied in health-care facilities and other relevant facilities.

There are noticeable changes in the national healthcare system because of the COVID-19 pandemic. Despite the challenges that are arising from the impact of the pandemic on TB control, this uncertain pandemic situation also provides several opportunities to improve TB control in the future. ${ }^{38}$ A study by Fatima et al on building better TB control systems in a post-COVID world highlighted several lessons to be learned. ${ }^{38}$ With similar symptoms (eg, cough, fever, and breathing difficulties), TB and COVID-19 can be confused, and stigma and fear concerning the new virus can affect patients' likelihood to seek health-care services. Nevertheless, this pandemic has given the insight to deal with this stigma and fear through enhancing the role of community and religious leaders. TB patients can experience the stigma against COVID-19, and it must be minimized because it would impact the success of TB treatment. ${ }^{35,36}$

\section{Conclusion}

The COVID-19 pandemic has posed a new challenge for the national TB control program. We identified several disruptions due to COVID-19 pandemic on TB control management, such as the decrease in government funding for TB treatment; lower quality of care and treatment for TB, MDR-TB, and TB-HIV; decrease in TB case detection and rapid diagnostic services; and lower activities in monitoring, evaluation and surveillance. To reach the target with the end TB strategy, the government of Indonesia can adopt the WHO's comprehensive strategies, such as integrated, patient-centered TB care and prevention strategies; bold policies and supportive systems; and intensified research and innovations.

\section{Funding}

This study was funded by Universitas Padjadjaran through the Centre of Excellence in Higher Education for Pharmaceutical Care Innovation.

\section{Disclosure}

The authors declare no conflicts of interest for this work.

\section{References}

1. Global tuberculosis report 2020 [Internet]; [cited February 8, 2021]. Available from: https://www.who.int/publications/i/item/9789240013131. Accessed January 13, 2022.

2. National Strategic Plan on Tuberculosis (2016-2020). eToolkits [Internet]; [cited June 11, 2021]. Available from: http://etoolkits.dghs.gov.bd/ toolkits/bangladesh-program-managers/national-strategic-plan-tuberculosis-2016-2020. Accessed January 13, 2022.

3. Tola HH, Tol A, Shojaeizadeh D, Garmaroudi G. Tuberculosis treatment non-adherence and lost to follow up among TB patients with or without HIV in developing countries: a systematic review. Iran J Public Health. 2015;44(1):1-11.

4. WHO Coronavirus (COVID-19) dashboard [Internet]; [cited June 11, 2021]. Available from: https://covid19. who.int. Accessed January 13, 2022.

5. Parikh PA, Shah BV, Phatak AG, et al. COVID-19 pandemic: knowledge and perceptions of the public and healthcare professionals. Cureus. 2020;12 (5):e8144. doi:10.7759/cureus.8144

6. CDC. Labs [Internet]. Centers for Disease Control and Prevention; 2020 [cited June 11, 2021]. Available from: https://www.cdc.gov/coronavirus/ 2019-ncov/lab/testing.html. Accessed January 13, 2022.

7. WHO. The end TB strategy; [cited February 8, 2021]. Available from: https://www.who.int/tb/End_TB_brochure.pdf. Accessed January 13, 2022.

8. Okeahalam C, Williams V, Otwombe K. Factors associated with COVID-19 infections and mortality in Africa: a cross-sectional study using publicly available data. BMJ Open. 2020;10(11):e42750. doi:10.1136/bmjopen-2020-042750 
9. Pang Y, Liu Y, Du J, Gao J, Li L. Impact of COVID-19 on tuberculosis control in China. Int J Tuberc Lung Dis. 2020;24(5):545-547. doi:10.5588/ ijtld.20.0127

10. WHO. Treatment of tuberculosis: guidelines for national programmes [Internet]. World Health Organization; [cited November 14, 2020]. Available from: https://www.who.int/tb/features_archive/new_treatment_guidelines_may2010/en/. Accessed January 13, 2022.

11. Therapeutics and COVID-19: living guideline [Internet]; [cited June 11, 2021]. Available from: https://www.who.int/publications-detail-redirect /WHO-2019-nCoV-therapeutics-2021.1. Accessed January 13, 2022.

12. Yang H, Lu S. COVID-19 and tuberculosis. J Transl Intern Med. 2020;8(2):59-65. doi:10.2478/jtim-2020-0010

13. Evaluation of Xpert MTB-RIF guided diagnosis and treatment of rifampicin-resistant tuberculosis in Indonesia: a retrospective cohort study [Internet]; [cited June 11, 2021]. Available from: https://journals.plos.org/plosone/article?id=10.1371/journal.pone.0213017. Accessed January 13, 2022.

14. WHO. What is DOTS? [Internet]. World Health Organization; [cited November 14, 2020]. Available from: https://www.who.int/tb/publications/ dots-who-guide/en/. Accessed January 13, 2022.

15. National Institutes of Health. Coronavirus Disease 2019 (COVID-19) Treatment Guidelines; 2021 [cited February 8, 2021]. Available from: https:// files.covid19treatmentguidelines.nih.gov/guidelines/covid19treatmentguidelines.pdf. Accessed January 13, 2022.

16. COVID-19 WRP. Peta sebaran COVID-19 [Internet]. covid19.go.id; [cited June 11, 2021]. Available from: https://covid19.go.id/peta-sebarancovid19. Accessed January 13, 2022.

17. USAID. Controlling tuberculosis in Indonesia; [cited February 8, 2021]. Available from: https://www.usaid.gov/indonesia/fact-sheets/reducingmultidrug-resistant-tuberculosis-indonesia. Accessed January 13, 2022.

18. Economic and social impacts of COVID-19: updates from the listening to Tajikistan survey [Internet]. World Bank; [cited June 16, 2021]. Available from: https://www.worldbank.org/en/news/factsheet/2020/07/13/economic-and-social-impacts-of-covid-19-update-from-listening-to-tajikistan. Accessed January 13, 2022.

19. World Health Organization. Global Tuberculosis Report 2021. Geneva: World Health Organization; 2021.

20. Boyce MR, Attal-Juncqua A, Lin J, et al. Global fund contributions to health security in ten countries, 2014-20: mapping synergies between vertical disease programmes and capacities for preventing, detecting, and responding to public health emergencies. Lancet Glob Health. 2021;9(2):e181e188. doi:10.1016/S2214-109X(20)30420-4

21. Roberts L. How COVID hurt the fight against other dangerous diseases. Nature. 2021;592(7855):502-504. doi:10.1038/d41586-021-01022-x

22. Respon tuberkulosis di Indonesia lebih buruk selama pandemi Covid-19; October 03, 2021.

23. Chan G, Triasih R, Nababan B, et al. Adapting active case-finding for TB during the COVID-19 pandemic in Yogyakarta, Indonesia. Public Health Action. 2021;11(2):41-49. doi:10.5588/pha.20.0071

24. Klinton JS, Heitkamp P, Rashid A, et al. One year of COVID-19 and its impact on private provider engagement for TB: a rapid assessment of intermediary NGOs in seven high TB burden countries. J Clin Tuberc Other Mycobact Dis. 2021;25:100277. doi:10.1016/j.jctube.2021.100277

25. WHO. Global TB progress at risk; 2021. Available from: https://www.who.int/news/item/14-10-2020-who-global-tb-progress-at-risk. Accessed January 13, 2022.

26. Pathak S, Jolly MK, Nandi D. Countries with high deaths due to flu and tuberculosis demonstrate lower COVID-19 mortality: roles of vaccinations. Hum Vaccin Immunother. 2021;17(9):2851-2862. doi:10.1080/21645515.2021.1908058

27. Labkes Prov. Jabar - Labkes Jabar 2020 [Internet]; [cited June 11, 2021]. Available from: https://www.labkesprovjabar.id/. Accessed January 13, 2022.

28. Alene KA, Wangdi K, Clements ACA. Impact of the COVID-19 pandemic on tuberculosis control: an overview. Trop Med Infect Dis. 2020;5 (3):123. doi:10.3390/tropicalmed5030123

29. Akhtar MM, Alotaibi ST, Althubeti AF, et al. The potential impact of COVID-19 infection on tuberculosis: a literature review. Int J Community Med Public Health. 2021;8(2):937. doi:10.18203/2394-6040.ijcmph20210066

30. Antaranews.com. COVID-19 pandemic impedes efforts to control tuberculosis [Internet]. Antara News; [cited June 11, 2021]. Available from: https://en.antaranews.com/news/170742/covid-19-pandemic-impedes-efforts-to-control-tuberculosis. Accessed January 13, 2022.

31. World Health Organization. COVID-19: considerations for tuberculosis (TB) care [Internet]; 2020 [cited May 10, 2021]. Available from: https:// www.who.int/docs/default-source/hq-tuberculosis/covid-19-tb-clinical-management-info-note-dec-update-2020.pdf?sfvrsn=554b68a7_0. Accessed January 13, 2022.

32. Awasthi AK, Singh PK. Tuberculosis management in India during COVID-19 crisis. J Public Health Policy. 2021;42(1):185-189. doi:10.1057/ s41271-020-00265-8

33. Malik AA, Safdar N, Chandir S, et al. Tuberculosis control and care in the era of COVID-19. Health Policy Plan. 2020;35(8):1130-1132. doi:10.1093/heapol/czaa109

34. Crisan-Dabija R, Grigorescu C, Pavel C-A, et al. Tuberculosis and COVID-19: lessons from the past viral outbreaks and possible future outcomes. Can Respir J. 2020;2020:1-10. doi:10.1155/2020/1401053

35. Khan MS, Rego S, Rajal JB, et al. Mitigating the impact of COVID-19 on tuberculosis and HIV services: a cross-sectional survey of 669 health professionals in 64 low and middle-income countries. Di Gennaro F, editor. PLoS One. 2021;16(2):e0244936. doi:10.1371/journal.pone.0244936

36. Oga-Omenka C, Tseja-Akinrin A, Boffa J, Heitkamp P, Pai M, Zarowsky C. Commentary: lessons from the COVID-19 global health response to inform TB case finding. Healthcare. 2021;9(2):100487. doi:10.1016/j.hjdsi.2020.100487

37. Visca D, Ong CWM, Tiberi S, et al. Tuberculosis and COVID-19 interaction: a review of biological, clinical and public health effects. Pulmonology. 2021;27(2):151-165. doi:10.1016/j.pulmoe.2020.12.012

38. Fatima R, Akhtar N, Yaqoob A, Harries AD, Khan MS. Building better tuberculosis control systems in a post-COVID world: learning from Pakistan during the COVID-19 pandemic. Int J Infect Dis. 2021;113:S88-S90. doi:10.1016/j.ijid.2021.03.026 


\section{Publish your work in this journal}

The Journal of Multidisciplinary Healthcare is an international, peer-reviewed open-access journal that aims to represent and publish research in healthcare areas delivered by practitioners of different disciplines. This includes studies and reviews conducted by multidisciplinary teams as well as research which evaluates the results or conduct of such teams or healthcare processes in general. The journal covers a very wide range of areas and welcomes submissions from practitioners at all levels, from all over the world. The manuscript management system is completely online and includes a very quick and fair peer-review system. Visit http://www.dovepress.com/testimonials.php to read real quotes from published authors.

Submit your manuscript here: https://www.dovepress.com/journal-of-inflammation-research-journal 